CLINICAL STUDY

\title{
Cushing's syndrome due to intermittent ectopic ACTH production showing a temporary remission during a pulmonary infection
}

\author{
Alessandro Peri, Donatella Bemporad, Gabriele Parenti, Paola Luciani, Mario Serio and Massimo Mannelli \\ Endocrine Unit, Department of Clinical Physiopathology, University of Florence, Florence, Italy \\ (Correspondence should be addressed to M Mannelli, Department of Clinical Physiopathology, Endocrine Unit, University of Florence, Viale Pieraccini 6 , \\ 50139 Florence, Italy; Email: m.mannelli@dfc.unifi.it)
}

\begin{abstract}
Objectives: In about 15-20\% of patients with ACTH-dependent Cushing's syndrome the source of ACTH is outside the pituitary gland. Pulmonary tumours are the most frequent, yet not unique, source of ectopic ACTH. In some instances the localisation of an ACTH-secreting tumour may be problematic. Occult ectopic ACTH secretion indicates the occurrence of ACTH-dependent hypercortisolism with an unknown origin. Another peculiarity of Cushing's syndrome may reside in the episodic cortisol hypersecretion, which can determine a pattern characterised by hypercortisolism together with periods of remission (cyclic Cushing's syndrome). We describe a very challenging case of Cushing's syndrome due to ectopic ACTH hypersecretion, showing virtually all of the most unusual features of the disease.

Design: A 55-year-old woman affected by Cushing's syndrome, presenting with biochemical features of ectopic ACTH secretion, has been followed for 7 years.

Methods: Thorough basal and dynamic hormonal assessment through the past 7 years is reported. In addition, the results of extensive imaging studies are presented.

Results: The source of ACTH secretion has not been identified so far, and hypercortisolism has been controlled by octreotide treatment. In addition, the patient showed a cyclic pattern of hypercortisolism with a long-term remission period. A unique feature of this case is represented by the fact that we observed a temporary, yet dramatic, short-lasting remission of ACTH and cortisol hypersecretion during a pulmonary infection, which occurred while the patient was hospitalised for a periodic hormonal assessment.

Conclusions: This case well represents the wide spectrum of clinical variability of Cushing's syndrome. Most interestingly, to our knowledge, this is the first report of a case of Cushing's syndrome showing a remission during an acute infection.
\end{abstract}

European Journal of Endocrinology 145 605-611

\section{Introduction}

Ectopic adenocorticotrophin (ACTH) secretion accounts for approximately $15-20 \%$ of cases of ACTH-dependent Cushing's syndrome. The most common cause of ectopic ACTH secretion is represented by small cell lung cancer $(1,2)$, but other tumours such as bronchial carcinoids, pancreatic neuroendocrine tumours and phaeochromocytomas may be the source of ACTH secretion. In cases of overt ectopic ACTH secretion (EAS), the features at presentation are clear and the results of dynamic tests (dexamethasone suppression, corticotrophin-releasing hormone (CRH) and desmopressin stimulation), together with a radiological evaluation allow the formulation of a correct diagnosis (3). However, distinguishing between
Cushing's disease (CD) and EAS may turn out to be a challenging dilemma when the source of ACTH secretion is not apparent on radiological examination (occult ectopic ACTH secretion, oEAS) and the interpretation of the clinical and biochemical features is equivocal (1-5). In such instances simultaneous bilateral inferior petrosal sinus (IPS) catheterisation and sampling, with CRH stimulation, has been reported to approach $100 \%$ sensitivity and specificity in distinguishing patients with $\mathrm{CD}$ from patients with EAS (6). However, localising the source of EAS may still be cumbersome and in several cases the site of the tumour remains unknown or it becomes evident from months to years after the diagnosis of hypercortisolism (2). Some authors have reported the identification of microscopic multiple pulmonary carcinoids, named 
tumourlets, responsible for ACTH hypersecretion $(7,8)$. New perspectives in the localisation of ectopic ACTHsecreting tumours have been provided by the introduction of ${ }^{111}$ In-DTPA-octreotide scintigraphy. The presence of somatostatin receptors has been indeed proved to be of some help in the localisation of these tumours (9-12). However, there is not a general agreement on this issue and some authors have reported a low diagnostic yield with scintigraphy (13). The clinical introduction of somatostatin analogues also opened the field to new pharmacological approaches for the control of hypercortisolism. The somatostatin analogue octreotide has been shown to be effective in reducing cortisol levels in several reports (9, $10,14,15)$. As a matter of fact, the modern diagnostic procedures and therapeutic options for Cushing's syndrome should warrant an accurate diagnosis and treatment schedule. However, this is not always the case. Additional and unexpected problems can be encountered, such as in those cases of Cushing's syndrome in which episodic cortisol hypersecretion occurs. Cyclic Cushing's syndrome is most frequently associated with a pituitary adenoma (16), but it has also been described in EAS (17).

Here we describe the complex case of a 55-year-old woman with oEAS, showing a cyclic hypercortisolaemic pattern, who has been observed since 1994 at our University Hospital.

\section{Case report}

In April 1994 a 49-year-old woman was admitted to the Endocrine Unit ward at the University Hospital, with an 8 year history of arterial hypertension, not satisfactorily controlled by specific therapy (angiotensinconverting enzyme (ACE) inhibitor, thiazides). In the previous year she had experienced a weight gain of about $10 \mathrm{~kg}$ and she had noticed increasing hypertricosis, skin pigmentation, seborrhoea and proximal muscle weakness. On admission the patient presented with a round plethoric face, truncal obesity and increased skin pigmentation, particularly over the knuckles, and hypertricosis. Continuous blood pressure recording revealed a moderate-severe hypertensive pattern, without nocturnal decrease. The main laboratory values were within the normal range. Baseline evaluation revealed ACTH-dependent hypercortisolism: ACTH $97.2 \mathrm{ng} / \mathrm{l}$ (normal value (n.v.) 9-52); urinary free cortisol (UFC) $1931 \mathrm{nmol} / 24 \mathrm{~h}$ (n.v. <275); serum cortisol at $0800 \mathrm{~h} 437 \mathrm{nmol} / \mathrm{l}$ (n.v. 160-690), serum cortisol at $2400 \mathrm{~h} 352 \mathrm{nmol} / \mathrm{l}$ (n.v. 25-250). Anterior pituitary evaluation did not show any abnormal value, besides ACTH. Dehydroepiandrosterone sulphate (DHEAS,) $\Delta 4$ androstenedione, $17 \mathrm{OH}$-progesterone and testosterone were within the normal range. CRH stimulation $(100 \mu \mathrm{g}$ i.v. $)$ did not produce any significant increase in ACTH and cortisol levels (Fig. 1). Two-day high-dose dexamethasone

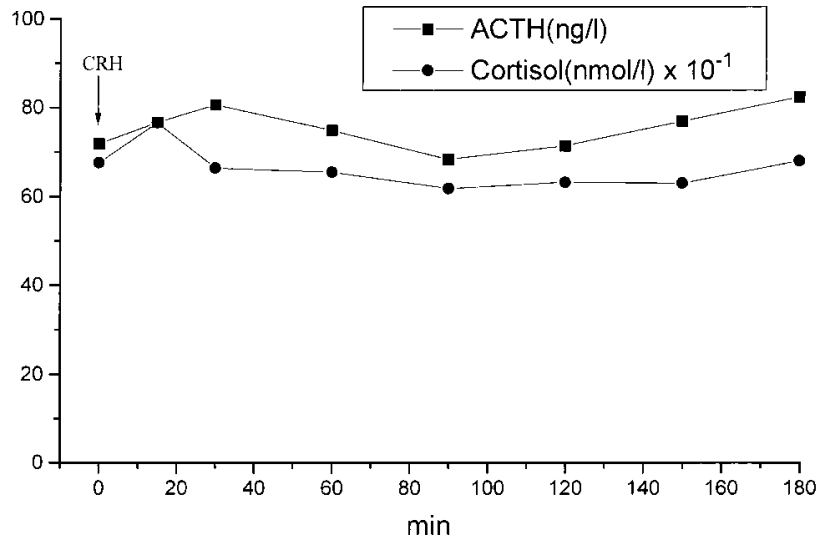

Figure 1 Results of CRH testing (April 1994).

resulted in lack of suppression (ACTH before dexamethasone $64.2 \mathrm{ng} / \mathrm{l}$, after dexamethasone $65.3 \mathrm{ng} / \mathrm{l}$; cortisol before dexamethasone $533 \mathrm{nmol} / \mathrm{l}$, after dexamethasone $512 \mathrm{nmol} / \mathrm{l})$. These results suggested an ectopic source of ACTH. Additionally, the injection of $100 \mu \mathrm{g}$ octreotide s.c. revealed a $66 \%$ (3 h after the injection) and a 31\% (5 h after the injection) reduction of ACTH and cortisol levels respectively (Fig. 2).

\section{Imaging procedures}

Magnetic resonance imaging (MRI) of the pituitary region showed an empty sella pattern without signs suggesting the presence of an adenoma (Fig. 3A and B). Computed tomography (CT) of the chest and the abdomen revealed no remarkable abnormality, with the exception of a severely hypotrophic left kidney, related to chronic pyelonephritis. Renal scintigraphy confirmed the functional exclusion of the left kidney. A ${ }^{111}$ In-DTPA-octreotide scan with single-photon emission computed tomography acquisitions at 5 and $24 \mathrm{~h}$ after injection was negative.

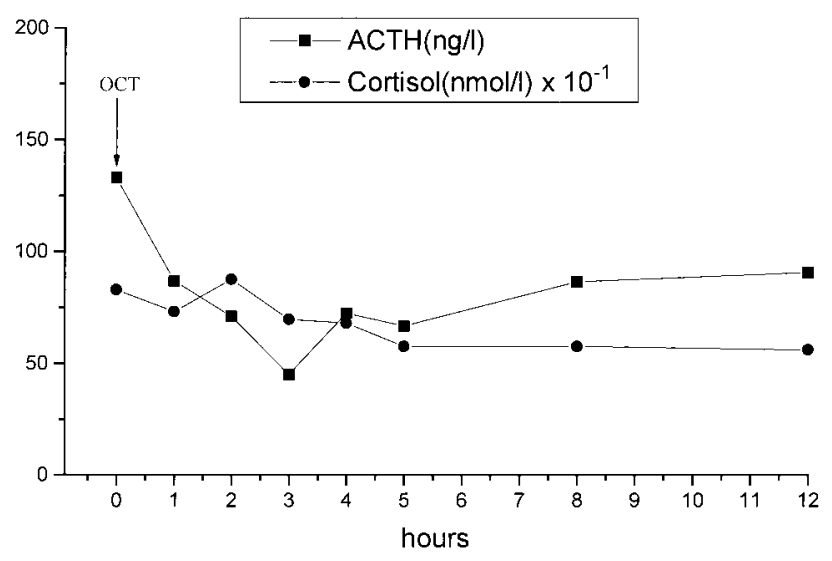

Figure 2 Response to octreotide s.c. injection (April 1994). 


\section{Bilateral IPS ACTH sampling}

ACTH levels in plasma drawn before and after i.v. CRH $(100 \mu \mathrm{g})$ from both the IPSs were determined. The basal IPS:peripheral (IPS:P) ACTH ratio was 1.53 for the right (164 vs $107 \mathrm{ng} / \mathrm{l})$ and 1.37 for the left IPS (147 vs $107 \mathrm{ng} / \mathrm{l}$ ), resulting in a right-to-left gradient of 1.12. Following CRH stimulation, the IPS:P ACTH ratio after $5 \mathrm{~min}$ was 1.59 for the right (162 vs $102 \mathrm{ng} / \mathrm{l}$ ) and 1.47 for the left IPS (150 vs $102 \mathrm{ng} / \mathrm{l}$ ). These results further suggested a diagnosis of EAS. In fact, an IPS:P gradient higher than 2 (basal or after $\mathrm{CRH})$ has been found to show high accuracy (97\% sensitivity and $100 \%$ specificity) in diagnosing CD in a series of 128 patients (6).

\section{ACTH multiple venous sampling}

Because of the presence of the severely hypotrophic, non-functioning left kidney, a catheterisation of the renal veins was performed for the measurement of the plasma renin activity (PRA) ratio. During this examination, in spite of the low sensitivity reported on catheterisation studies for the localisation of EAS (18), we decided to extend plasma sampling at different levels of the main venous tree. The purpose of the additional sampling was to look for a gradient in ACTH concentration, indicating the ectopic source of secretion. Whereas a significant PRA gradient was found (left $21.3 \mu \mathrm{g} / \mathrm{l}$ per $\mathrm{h}$, right $11.3 \mu \mathrm{g} / \mathrm{l}$ per $\mathrm{h}$ ), suggesting a renal involvement in the pathogenesis of hypertension, no ACTH gradient was found.

\section{Follow-up}

1994-1995 The patient underwent left nephrectomy in May 1994. During surgery left adrenalectomy was also performed as a first step to eliminate hypercortisolism through adrenalectomy, and accurate abdominal exploration, including a direct ultrasonography of the pancreas, excluded the presence of pathological findings. Hypercortisolism persisted after left adrenalectomy, although to a lesser extent (UFC $570 \mathrm{nmol} /$ $24 \mathrm{~h}$ ). Considering the good response, in terms of ACTH and cortisol levels, after octreotide s.c. injection, the patient was discharged with the following therapy: octreotide $0.1 \mathrm{mg}$ s.c. every $8 \mathrm{~h}$, plus antihypertensive treatment (ACE inhibitor+hydroclorothiazide).

The patient has been re-evaluated in our unit at the University Hospital on many occasions since then. In January 1995 ACTH was $22 \mathrm{ng} / \mathrm{l}$, serum cortisol was $348 \mathrm{nmol} / \mathrm{l}$ at $0800 \mathrm{~h}$ and $150 \mathrm{nmol} / \mathrm{l}$ at $2400 \mathrm{~h}$, UFC was $60.8 \mathrm{nmol} / 24 \mathrm{~h}$. Blood pressure levels appeared satisfactorily controlled. Two months later, due to poor compliance to s.c. injections three times a day, the patient decided to discontinue octreotide therapy.

In April 1995 ACTH was $98 \mathrm{ng} / \mathrm{l}$, serum cortisol $498 \mathrm{nmol} / \mathrm{l}$ at $0800 \mathrm{~h}$ and $431 \mathrm{nmol} / \mathrm{l}$ at $2400 \mathrm{~h}$, and UFC $838 \mathrm{nmol} / 24 \mathrm{~h}$. Since the patient consistently refused octreotide treatment, ketoconazole therapy was started (200 mg twice daily, oral administration).

Five months later ACTH $(42.3 \mathrm{ng} / \mathrm{l})$, serum cortisol $(418 \mathrm{nmol} / \mathrm{l}$ at $0800 \mathrm{~h}, 132 \mathrm{nmol} / \mathrm{l}$ at $2400 \mathrm{~h})$ and UFC (48.6 nmol/24) appeared normalised.

1996-1999 In February 1996, in consideration of the fact that ACTH and cortisol levels were consistently in the normal range and in view of the significant amelioration of the clinical features, it was decided to temporarily stop ketoconazole treatment. After 1 month off therapy ACTH was $32.2 \mathrm{ng} / \mathrm{l}$, serum cortisol $220 \mathrm{nmol} / \mathrm{l}$ at $0800 \mathrm{~h}$ and $111 \mathrm{nmol} / \mathrm{l}$ at $2400 \mathrm{~h}$, and UFC $58.8 \mathrm{nmol} / 24 \mathrm{~h}$. As these results were suggestive of clinical remission, ketoconazole was not recommended.

In the next three and a half years the patient was reevaluated many times and no sign of hypercortisolism was detected. She persistently reported a sense of well being and clinical assessment did not show any evidence of cortisol excess.

However, starting from September 1999 the patient noticed a bad control of blood pressure levels, despite the antihypertensive treatment she had never suspended (irbesartan, hydroclorothiazide, doxazosin at that time). In addition, she reported increasing weakness and weight gain. Her face appeared again round and plethoric. She was admitted to the University Hospital in November 1999. Overt hypercortisolism was shown by baseline tests: ACTH $199 \mathrm{ng} / \mathrm{l}$, serum cortisol $930 \mathrm{nmol} / \mathrm{l}(0800 \mathrm{~h}), 778 \mathrm{nmol} / \mathrm{l}(2400 \mathrm{~h})$, and UFC $2061 \mathrm{nmol} / 24 \mathrm{~h}$. DHEAS, $\Delta 4$ androstenedione, 170H-progesterone and testosterone were within the normal range. Plasma levels of chromogranin A were measured and found to be above the normal range (132.8 ng/ml; n.v. 31-122), whereas neuron-specific enolase was normal $(7.8 \mathrm{ng} / \mathrm{ml}$; n.v. O13). Similarly, calcitonin was within the normal range (5.1 pg/ml; n.v. <8.5). MRI of the pituitary region confirmed the presence of an empty sella, without signs of pituitary adenoma. During the time the patient remained hospitalised, she experienced hyperthermia. A chest X-ray revealed a pulmonary infection (Fig. 4A), which was treated with antibiotic therapy (amoxicillin, erythromycin). Hyperthermia lasted for 5 days and showed a remittent pattern with a peak of $39{ }^{\circ} \mathrm{C}$. A marked reduction of the parenchymal infiltration was observed after 1 week (Fig. 4B). Surprisingly, concomitant with the lung infection, ACTH $(27.6 \mathrm{ng} / \mathrm{ml})$ and cortisol $(403 \mathrm{nmol} / \mathrm{l}$ at $0800 \mathrm{~h}$ and $120 \mathrm{nmol} / \mathrm{l}$ at $2400 \mathrm{~h})$ levels dropped down into the normal range. UFC was $<25 \mathrm{nmol} / 24 \mathrm{~h}$. In addition, antihypertensive treatment had to be interrupted because of marked hypotension. Hormonal re-assessment in the following days confirmed the absence of hypercortisolism. The patient was therefore discharged without any hypercortisolism-related therapy. 


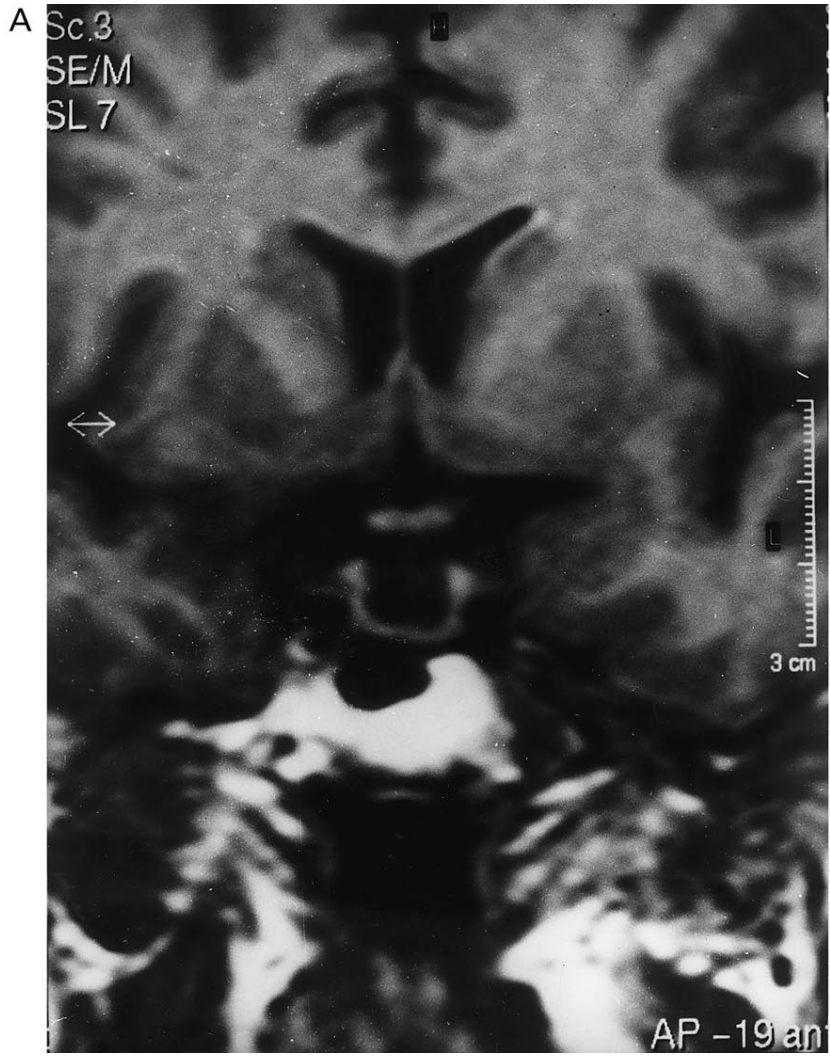

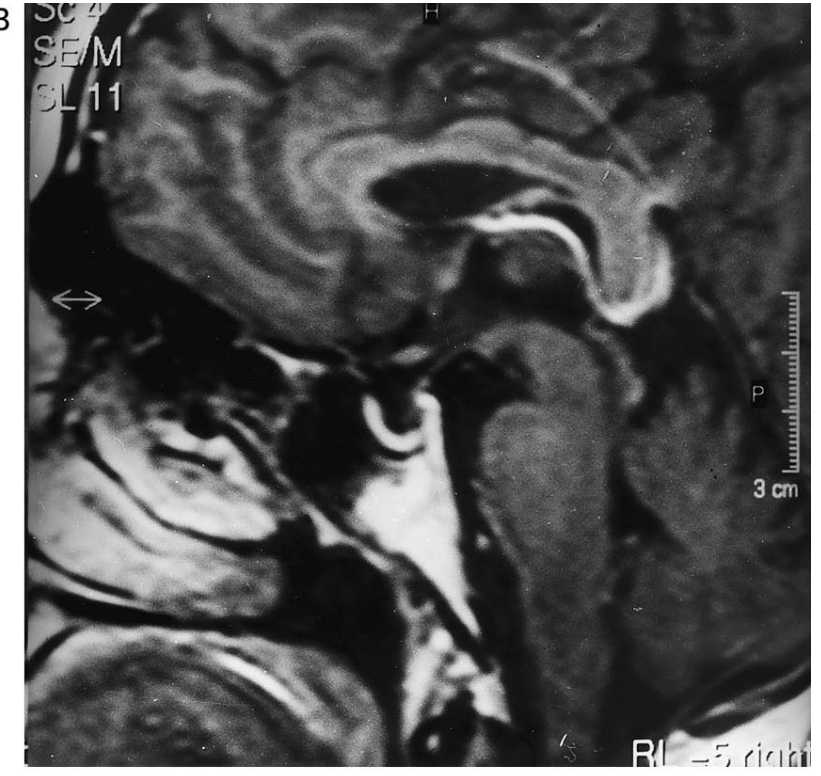

Figure $3 \mathrm{MRI}$ of the pituitary region, showing a pattern of empty sella. (A) Frontal view; (B) sagittal view (April 1994).
2000 The patient felt well for about 1 month. Thereafter, she experienced again muscle weakness and weight gain. During hospitalisation, hormonal assessment revealed once again hypercortisolism (ACTH $180 \mathrm{ng} / \mathrm{ml}$; cortisol $1140 \mathrm{nmol} / \mathrm{l}$ at $0800 \mathrm{~h}$ and $1228 \mathrm{nmol} / \mathrm{l}$ at $2400 \mathrm{~h}$; UFC $1520 \mathrm{nmol} / 24 \mathrm{~h}$ ). Octreotide s.c. injection $(100 \mu \mathrm{g})$ produced again a decrease of ACTH $(64 \% 3 \mathrm{~h}$ after the injection) and cortisol levels $\left(54 \% 5 \mathrm{~h}\right.$ after the injection). A ${ }^{111} \mathrm{In}-$ DTPA-octreotide scan was performed again and was confirmed to be negative, as well as a positron emission tomography (PET) scan. A new CT scan of the chest and of the abdomen (February 2000) did not show any pathological finding, besides an increased volume of the right adrenal gland (the left adrenal had been previously removed). Treatment with octreotide LAR (30 mg i.m. every 28 days) was started. A reevaluation of the patient 3 months after the initiation of octreotide treatment revealed normalisation of ACTH (33.9 ng/l), serum cortisol (301 nmol/l at $0800 \mathrm{~h}$, $52 \mathrm{nmol} / \mathrm{l}$ at $2400 \mathrm{~h}$ ) and UFC $(54 \mathrm{nmol} / 24 \mathrm{~h})$. In September 2000 dexamethasone (2 mg overnight) caused a normal suppression of ACTH (27.3 vs $12.6 \mathrm{ng} / \mathrm{l}$ ) and cortisol (303 vs $34 \mathrm{nmol} / \mathrm{l}$ ). The patient is currently under octreotide LAR treatment and her ACTH and cortisol plasma levels are persistently within the normal range.

\section{Discussion}

The diagnosis of Cushing's syndrome may turn out to be sometimes a complex and time-consuming challenge in clinical endocrinology. The diagnostic pathway includes a multi-step approach; after the assessment of hypercortisolism, it has to be determined whether cortisol excess is ACTH-dependent or not. In the former case, further evaluation should provide information about the pituitary or ectopic source of ACTH secretion.

In this report we described the case of a patient with a long-term history of ACTH-dependent hypercortisolism. The ectopic source of ACTH was indirectly established on the basis of biochemical and imaging procedures. In fact, the lack of response to $\mathrm{CRH}$ testing, the absent ACTH/cortisol suppression after 2 day highdose dexamethasone, the results of the bilateral IPS sampling and of the pituitary MRI are consistent with an ectopic source of ACTH secretion. None of the localisation procedures we performed (CT of the chest and of the abdomen, abdomen exploration during surgery for nephrectomy, multiple venous sampling, ${ }^{111}$ In-DTPA-octreotide and PET scan) was able to localise the source of ACTH secretion. EAS is a well known entity $(1,2)$, which has to be differentiated from CD; with oEAS the diagnosis is indirectly achieved through multiple biochemical and radiological 


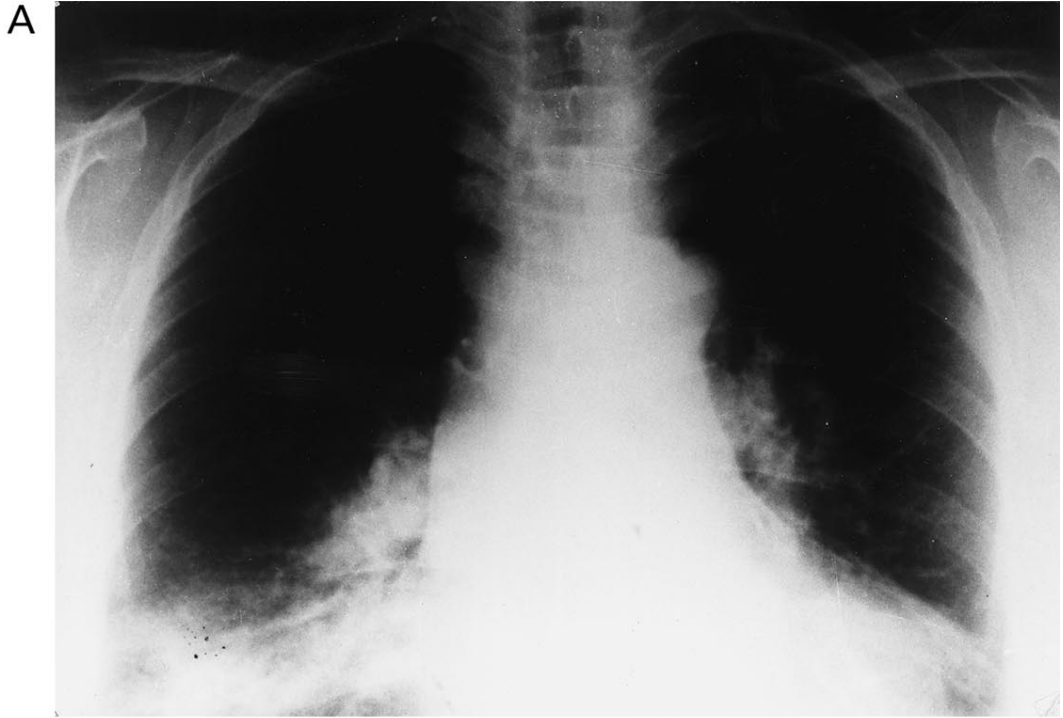

B

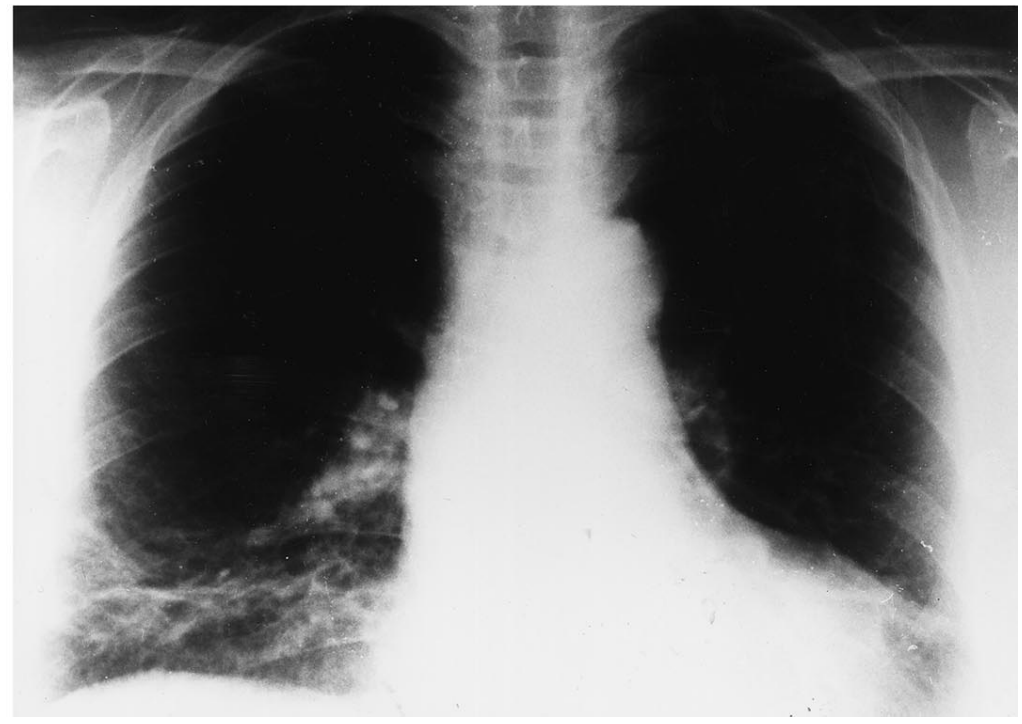

Figure 4 X-ray of the chest (November 1999). (A) Presence of parenchymal infiltration in the right lower lobe; (B) partial resolution 1 week later. procedures. In this regard, the 7 year clinical history of our patient is self-explanatory. The diagnosis of oEAS could be formulated on the basis of the extensive laboratory and imaging-based evaluation, which was of no help in demonstrating the site of ACTH hypersecretion. Noticeably, in spite of an evident and repeated decrease of ACTH and cortisol levels after octreotide injection, ${ }^{111}$ In-DTPA-octreotide scans were negative. The presence of subcentimetric lesion(s) possibly not detected by imaging procedures, yet sensitive to octreotide administration, might be hypothesised. Small cell lung cancer and bronchial carcinoid tumours are among the most common causes of EAS $(1,2)$. The clinical history of our patient seems to exclude a lung cancer. The smallest carcinoids are called tumourlets $(19,20)$, which are nodules with a diameter of less than $5 \mathrm{~mm}$ (19). Multiple peripheral tumourlets have been described in a very few cases as the cause of EAS, as assessed by open-lung biopsy and subsequent histological examination $(7,8)$. The search for tumour markers (i.e. ACTH precursors, calcitonin, gut hormones, oncofetal proteins, $\beta$-human chorionic gonadotrophin, and amine precursor uptake and decarboxylation (APUD) markers), which are found to be increased (one or more) in about two-thirds of patients with EAS, may be of some help in better defining the diagnosis (2). Chromogranins, and mostly chromogranin A, which was above the upper normal range in our patient, have been shown to have the highest sensitivity in determining the neuroendocrine nature of a tumour (21). Whether the case we reported fits into the category of pulmonary tumourlets remains to be demonstrated, but at present this appears to be a suggestive hypothesis. In one of the cases of EAS due to pulmonary tumourlets that have been described in the literature, micronodular lesions 
were identified 10 years after the diagnosis of hypercortisolism (7).

An additional peculiarity of our patient is the cyclic pattern of hypercortisolism, demonstrated by the clinical and biochemical remission observed 2 years after the diagnosis of hypercortisolism. The free-ofdisease period lasted for three and a half years, a quite unusual long-term remission, before recurrence. Cyclic Cushing's syndrome is characterised by episodic cortisol hypersecretion and it is most frequently caused by $\mathrm{CD}$. However, intermittent hypercortisolism with long periods of remission has been observed in EAS, as in our case, resulting in some instances in misinterpretation of laboratory investigations (2).

An intriguing feature of our patient is represented by the dramatic, yet temporary, drop of ACTH and cortisol levels during a pulmonary infection, which occurred in a period of overt hypercortisolism (ACTH $199 \mathrm{ng} / \mathrm{l}$; serum cortisol $930 \mathrm{nmol} / \mathrm{l}$ at $0800 \mathrm{~h}, 778 \mathrm{nmol} / \mathrm{l}$ at $2400 \mathrm{~h}$; UFC $2061 \mathrm{nmol} / 24 \mathrm{~h}$ ). It is well known that endogenous or exogenous hypercortisolism, causing mostly alterations of cell-mediated immunity $(22,23)$, may be complicated by opportunistic infections (24). In cases of endogenous hypercortisolism the likelihood for a bacterial or opportunistic infection is greatest in patients with markedly high levels of ACTH and cortisol, as it is observed in EAS (25). Therefore, whereas the occurrence of an infection in our patient was not an unexpected phenomenon, admittedly the fall of cortisol levels during the infection remains unexplained. Keeping in mind that no conclusive explanation can be provided, the characteristics of the remission, which was abrupt, remarkable, shortlasting and chronologically associated with the acute pulmonary infection, suggest that the inflammatory process may have caused the temporary remission. In this regard, it is known that various inflammatory cytokines have antitumour properties. Among these cytokines, tumour necrosis factor (TNF)- $\alpha$ has been demonstrated to have the strongest antitumour activity, by inducing both cell apoptosis and haemorrhagic necrosis (26). Although limited by severe toxicity (27), the clinical use of TNF- $\alpha$ has been preliminarily shown to have beneficial effects in highly malignant tumours, such as unresectable liver tumours (28).

The patient is currently under octreotide LAR treatment and her clinical and biochemical evaluation continues to be completely satisfactory. In this scenario medical treatment along with periodic screening was considered the best option, instead of performing right adrenalectomy and treating the patient for iatrogenic Addison's disease (previous left adrenalectomy). It is difficult to say whether the normal adrenocortical function is at present dependent on octreotide therapy or on a period of spontaneous remission. The inhibitory effect of octreotide is nevertheless well documented in our patient by the capability of the drug to promptly interrupt cortisol hypersecretion at the beginning of every therapeutic cycle.

In summary, we described here a very challenging case of Cushing's syndrome due to EAS, in which the source of ACTH secretion has not been determined so far, despite extensive examination. Considering that Cushing's syndrome may present with a wide variability of clinical and biochemical features, the quite peculiar characteristic of our patient is represented by the simultaneous presence of virtually all of the most unusual characteristics of the disease. In addition, to our knowledge, this is the first report of a patient with Cushing's syndrome who has experienced a temporary remission from the disease during an acute infection. We are still following our patient, and further assessment in the time to come hopefully will provide new and revealing information.

\section{References}

1 Orth DN. Cushing's syndrome. New England Journal of Medicine $1995332791-803$.

2 Wajchenberg BL, Mendonca BB, Liberman B, Pereira MA, Carneiro PC, Wakamatsu A et al. Ectopic adrenocorticotropic hormone syndrome. Endocrine Reviews $199415752-787$.

3 Invitti C, Pecori Giraldi F, De Martin M, Cavagnini F \& the Study Group of the Italian Society of Endocrinology on the Pathophysiology of the Hypothalamic-Pituitary-Adrenal axis. Diagnosis and management of Cushing's syndrome: results of an Italian multicentre study. Journal of Clinical Endocrinology and Metabolism 199984 440-448.

4 Newell-Price J, Perry L, Medbak S, Manson J, Savage M, Besser M et al. A combined test using desmopressin and corticotropinreleasing hormone in the differential diagnosis of Cushing's syndrome. Journal of Clinical Endocrinology and Metabolism 1997 82 176-181.

5 Dickstein G, Rowan-DeBold C, Galtan D, De Cherney GS, Jackson RV, Sheldon WR et al. Plasma corticotropin and cortisol responses to ovine corticotropin-releasing hormone (CRH), arginine vasopressin (AVP), CRH plus AVP, and $\mathrm{CRH}$ plus metyrapone in patients with Cushing's disease. Journal of Clinical Endocrinology and Metabolism 199681 2934-2941.

6 Kaltsas GA, Giannulis MG, Newell-Price JDC, Dacie JE, Thakkar C, Afshar $\mathrm{F}$ et al. A critical analysis of the value of simultaneous inferior petrosal sinus sampling in Cushing's disease and the occult ectopic adrenocorticotropin syndrome. Journal of Clinical Endocrinology and Metabolism $1999 \mathbf{8 4} 487-492$.

7 Arioglu E, Doppman J, Gomes M, Kleiner D, Mauro D, Barlow C et al. Cushing's syndrome caused by corticotropin secretion by pulmonary tumorlets. New England Journal of Medicine 1998339 883-886.

8 Ozbey N, Bozbora A, Kalayci G, Kapran Y, Yilmazbayhan D, Dizdaroglu F et al. Cushing's syndrome caused by ectopic corticotropin secretion by multiple peripheral pulmonary carcinoids and tumorlets of carcinoid type. Journal of Endocrinological Investigation 200023 536-541.

9 Lamberts SW, Hofland LJ, De Herder WW, Kwekkeboom DJ, Reubi JC \& Krenning EP. Octreotide and related somatostatin analogs in the diagnosis and treatment of pituitary disease and somatostatin receptor scintigraphy. Frontiers in Endocrinology $19931427-55$.

10 Phlipponneau M, Nocaudie M, Epelbaum J, De Kreyzer Y, Lalau JD, Marchandise X et al. Somatostatin analogs for the localization and preoperative treatment of an adrenocorticotropin-secreting bronchial carcinoid tumor. Journal of Clinical Endocrinology and Metabolism 199478 20-24. 
11 Krenning EP, Kwekkeboom DJ, Oei HY, De Jong RJ, Dop FJ, De Herder WW et al. Somatostatin receptor scintigraphy in carcinoids, gastrinomas and Cushing's syndrome. Digestion 199455 54-59.

12 Briganti V, Mannelli M, La Cava G, Peri A, Meldolesi U, Masi R et al. Characterizing an ectopic secreting carcinoid with indium111-DTPA-D-Phe-pentreotide. Journal of Nuclear Medicine 1997 38 711-718.

13 Tabarin A, Valli N, Chanson P, Bachelot Y, Rohmer V, BexBachellerie $\mathrm{V}$ et al. Usefulness of somatostatin receptor scintigraphy in patients with occult ectopic adrenocorticotropic syndrome. Journal of Clinical Endocrinology and Metabolism 1999 84 1193-1202.

14 Van den Bruel A, Bex M, Van Dorpe J, Heyns W \& Bouillon R. Occult ectopic ACTH secretion due to recurrent lung carcinoid: long-term control of hypercortisolism by continuous subcutaneous infusion of octreotide. Clinical Endocrinology $1998 \mathbf{4 9}$ 541-546.

15 Gill GV, Yong A, Power E \& Ramage J. Carcinoid-associated ectopic ACTH syndrome with variable response to octreotide. Postgraduate Medical Journal 1999 75 98-100.

16 Sakiyama R, Ashcraft WW \& Van Herle AJ. Cyclic Cushing's syndrome. American Journal of Medicine 1984 77 944-946.

17 Terzolo M, Ali A, Pia A, Bollito E, Reimondo G, Paccotti P et al. Cyclic Cushing's syndrome due to ectopic ACTH secretion by an adrenal pheochromocytoma. Journal of Endocrinological Investigation 199417 869-887.

18 Newell-Price J, Trainer P, Besser M \& Grossman A. The diagnosis and differential diagnosis of Cushing's syndrome and pseudoCushing's states. Endocrine Reviews 199819 647-672.

19 Whitwell F. Tumorlets of the lung. Journal of Pathology and Bacteriology 199570 529-541.
20 Davila GD, Dunn WF, Tazelarr HD \& Pairolero PC. Bronchial carcinoid tumors. Mayo Clinic Proceedings 199368 795-803.

21 Eriksson B, Arnberg H, Oberg K, Hellman U, Lundqvist G, Wernstedt $\mathrm{C}$ et al. A polyclonal antiserum against chromogranin $\mathrm{A}$ and B: a new sensitive marker for neuroendocrine tumours. Acta Endocrinologica 1990122 145-155.

22 Bailey JM. New mechanisms for effects of anti-inflammatory glucocorticoids. Biofactors 19913 97-102.

23 Auphan N, Di Donato JA, Rosette C, Helmeberg A \& Karin M. Immunosuppression by glucocorticoids: inhibition of NF-kB activity through induction of LkB synthesis. Science $1995 \mathbf{2 7 0}$ 286-290.

24 Aucott JN. Glucocorticoids and infection. Endocrinology and Metabolism Clinics of North America 199423 655-670.

25 Sarlis NJ, Chanock S \& Nieman L. Cortisolemic indices predict severe infections in Cushing syndrome due to ectopic production of adrenocorticotropin. Journal of Clinical Endocrinology and Metabolism $2000 \mathbf{8 5} 42-47$.

26 Wallach D, Boldin M, Varfolomeev E, Benyaert R, Vandenabeele P \& Fiers W. Cell death induction by receptors of the TNF family: towards a molecular understanding. FEBS Letters $1997 \mathbf{4 1 0} 96-106$.

27 Selby P, Hobbs S, Viner C, Jackson E, Jones A, Newell D et al. Tumor necrosis factor in man: clinical and biological observations. British Journal of Cancer 198756 803-808.

28 Nakamoto T, Inagawa H, Takagi K \& Soma GI. A new method of antitumor therapy with a high dose of TNF perfusion for unresectable liver tumors. Anticancer Research $2000 \mathbf{2 0}$ 4087-4096.

Received 12 April 2001

Accepted 17 July 2001 